\title{
DETERMINANTS OF TEACHERS' TURNOVER INTENTION IN BAHRIA SCHOOLS AND COLLEGES AT KARACHI
}

\author{
Rafique Ahmed Khan 1 \\ Bahria University Karachi Campus \\ 13, National Stadium Road, Karachi, Pakistan \\ Muhammad Ihsan Qadir ${ }^{2}$ \\ Bahria University Karachi Campus \\ 13, National Stadium Road, Karachi, Pakistan
}

\begin{abstract}
Purpose: This paper basically aims at exploring and investigating the impact of factors including career growth opportunities, workplace environment, managerial support, rewards \& recognition system, and work-life balance on 'turnover intention' of teachers, in Bahria Schools and Colleges at Karachi. For the sake of ascertaining influence of these factors on employee turnover intention, six Bahria Schools and Colleges at Karachi were chosen. Methodology: By adopting a quantitative approach, views of 120 respondents (both male \& female) were obtained with the help of a well structured questionnaire. The data were treated by applying correlation and regression analysis tools with the help of SPSS software, version 22.

Findings: The results indicated that all five factors were negatively related with teachers' turnover intention. However, impact of work-life balance was not insignificant. Similarly, results of the female employees varied from those of the male respondents. Male employees were comparatively less concerned about the issues related to work-life balance as compared to their female counterparts. Since all independent variables, if suitably practiced, also lead to employee satisfaction, the study clearly reflected the inverse relationship between employee satisfaction and turnover intention.

Implications: This study can help the management of Bahria Schools and Colleges to understand the factors responsible for employee turnover intention. By paying due attention towards the identified factors, the Bahria Schools and Colleges can significantly enhance the motivation level of teachers, thereby reducing their turnover intention. The study is considered equally useful for other Schools and Colleges. In the end, future researchers have been advised to further explore the likely contribution of other factors towards employee satisfaction and reduced turnover intention.
\end{abstract}

Keywords: Career Growth Opportunities, Workplace Environment, Rewards \& Recognition System, Management Support, Work-Life Balance, Turnover Intention.

* The material presented by the author does not necessarily portray the viewpoint of the editors and the management of the Institute of Business \& Technology (IBT)

1 Rafique Ahmed Khan

:rak@bimcs.edu.pk

2 Muhammad Ihsan Qadir

:miq@bimcs.edu.pk

(C) IBT-JBS is published by the Institute of Business and Technology (IBT).

Main Ibrahim Hydri Road, Korangi Creek, Karachi-75190, Pakistan. 


\section{INTRODUCTION}

Almost all leading organizations, irrespective of their size or the nature of business, try to maintain appropriate level of cohesiveness with employees by developing and motivating them. It is a universally recognized fact that long term retention of loyal and committed employees is the prime consideration of all employers who believe in maintaining a competitive edge through human resource. Excessive attrition and high turnover intention is neither in the interest of employer nor it is good for career progression of an employee. In the context of education sector, this is also critical for the private schools and colleges, especially in Mega cities like Karachi, either due to cultural issues or because of more job opportunities for the teachers. This problematic state can also be attributed to its instructional and fiscal impacts. Given the rising trend of opening new schools and colleges in private sector and in the present of tough competition prevalent in the education sector, this problem has been focus of many researchers and practitioners alike. However, most of the researchers have adopted segmented approaches which included teachers' job satisfaction, internal social factors and policy-related matters which have been used to identify the causes of teachers' perceived turnover intentions (Borman \& Dowling, 2008; Connolly \& James, 2006; Crossman \& Harris, 2006).

\subsection{Significance of Reduced Turnover Intention}

High turnover rate of teachers, leading to loss of the knowledge of experienced personnel is a source of concern for all leading education institutions in particular and other organizations in general, especially in the present era of knowledge workers (DeLong, 2004; Drucker, 1999). In educational institutions, the major point of concern for the management is the issues of teachers' job satisfaction and their turnover intention (Crossman \& Harris, 2006). In order to ensure long term retention of competent workers and reduce turnover intention, employers take a number of measures aimed at motivating and developing them; this helps them in maintaining a sustained competitive edge in the industry. Employee turnover intention can be termed as the intention of an employee to quit an organization. According to Price (1977), employee turnover can be measured in terms of a ratio between the number of employees who have left the company in a given time period and the average number of employees present during that timeframe. In the contemporary business environment, employee turnover intention has emerged as an important topic and is intertwined with employee retention. While employee retention has been included as a component of the competition criteria, turnover intention is related to employee satisfaction. Employee turnover intention can be termed as a process which is meant to encourage employees to continue their employment with their present organization for long time; in fact the inverse relationship between employee satisfaction and turnover intention is seen as a healthy sign for the organization. On the contrary, an organization that fails to keep its employees satisfied is not going to survive for long. Researchers have explored the fact that the employees who are dissatisfied may involve in non-productive, rather counter-productive activities such as social loafing, violation of norms, improper use of equipment, poor customer service, and sabotage (Spector, P. E., 1997). A number of studies have mentioned about the 
relationship between turnover intention and satisfaction (Bluedorn, 1982; Hollenbeck \& Williams, 1986; Tett \& Meyer, 1993).

According to (Frese, M., 1985), over-burdened and dissatisfied employees are usually found to face physical and mental disorder including stiffness in joints and muscles, tension, frustration, depression, lethargy, nervousness and insomnia. These problems ultimately lead to high level of turnover intention. Generally, there is an inverse relationship between effectiveness of employees' retention and their turnover intention, for betterment of an organization. It is beneficial not only for the organization but it is also in greater interest of employees, if they are appropriately managed. An organization having more committed and loyal employees usually proves to be more effective than its competitors, since happy workers are more productive (Robbins and Judge, 2007). Dissatisfied workers produce less output and are likely to switch over to a new organization as soon as they find an opportunity, leading to high turnover rate. Employee turnover rate, being a permanent termination from the organization, either voluntarily or involuntarily, does add into overall expense of the organization, both in the form of direct cost such as recruitment and selection, hiring temporary staff, management time etc., and the indirect costs like de-motivation, negative impact on remaining staff, and cost of training on products or services (Dess and Shaw, 2001). Therefore, in order to remain competitive, an organization should endeavor to keep its employee turnover rate to the bare minimum.

Although, there are no single universal measures which can deliver similar results in different cultures or business types, experts have identified a number of factors that can guarantee anticipated outcomes. Moreover, these measures have varying impact with regard to the time frame and gender difference. Like other employees, teachers of private schools and colleges of present era are not faced with challenges similar to what their predecessors had few decades ago; their needs, social trends, moral values, business ethics and the like, have been transformed by the global forces including the media and internet. The present era has brought a number of new opportunities, concurrent to the challenges. Due to the blessings of globalization, present day employees have become more confident, better informed and well connected with the outside world. As soon as they feel dissatisfied with the current employer or the job, they switch over to the next job. Career oriented teachers, who have enough potential for growth and also perceive lot of opportunities in their present organization, shall have quite a different turnover intention than the ones who either do not have sufficient potential for further growth or do not see any career opportunity for them. Long term retention of teachers, therefore, has the potential to create a win-win situation both for the faculty and the institution itself. In today's dynamic business environment, which is characterized by less predictability and more surprises, retention of better performers is becoming a real challenge. It is the responsibility of the institutions to take appropriate measures to retain their best faculty. If they fail to do that, they would lose good teachers and only the incompetent or incapable, having least job opportunities elsewhere, shall stay back. As opposed to their earlier counterparts, today's employers are finding it more difficult to keep the workers satisfied and committed. Employers have to pay more attention to the factors that are responsible for employee satisfaction, loyalty and 
retention. Any laxity in this endeavor shall tantamount to losing good employees which is a recognized recipe to organizational failure.

There are a number of studies which have been conducted on how important is the employee turnover intention and what are factors responsible for it, both at National and International level. As researched by Osteraker (1999), employee satisfaction and retention are the foundation stones for long term success of an organization. Turnover intension is not only an undesired factor, it is said to be a costly affair both for the employee and the employer; replacement cost is found to be quite high by the employers (Mitchell et al. 2001). As mentioned by Klein and Kozlowski, (2000); Raudenbush \& Bryk, (2002); Yammarino \& Danserau, (2004), as when an employee leaves a company, the employer loses not only the employee but also the loyal customers, ethical values and traditions. Employee retention is an important strategy for an organization, which begins with recruitment of the best available candidates and continues to implementing programs that keep employees happy, committed and engaged (Freyermuth, 2007).

\subsection{Problem Statement}

In the context of Pakistan, due to high degree of unemployment, teachers of private schools and colleges are not so comfortable in switching their job as compared to their counterparts in the developed world. For education sector, which is directly responsible for developing human resource, teachers' retention takes more implication. Like other business sectors, private schools and colleges are equally facing a tough competition and good faculty is head-hunted by the competitors. In private schools and colleges which have employed more female teachers than the males, turnover intention is comparatively low; this is perhaps due to less job opportunities for the females in other industries. Due to fear of losing good faculty, private schools are offering better salary packages and providing appropriate work environment to their teachers. This low turnover rate can be attributed to many environmental and political factors including excessive joblessness, job insecurity and other economical reasons. None-the-less, teachers having strong passion for teaching profession, and who are capable to teach a variety of subjects would always look for a better alternate job for obvious reasons. Through this study, an effort was made to study the relationship of teachers' turnover intention with career growth opportunities, workplace environment, managerial support, rewards \& recognition system, and work-life balance, in Bahria Schools and Colleges located at Karachi.

\section{LITERATURE REVIEW}

Although main causes of employee turnover intention are, more or less, similar across the organizations, many researchers have highlighted some factors which are culturally influenced. In this regards, a number of articles of renowned journals and publications were studied with an aim to quote only those publications which were credible and latest. According a study conducted by Morrell et al. (2004), 'turnover intention' is referred to deliberate cessation of employment in organization by an employee. The involuntary turnover also occurs when employees are forced to leave 
the organization, which may be triggered by reasons such as the real or perceived need to reduce costs, restructuring an organization or downsizing its structure; or for individual reasons related to an employee, such as poor performance, due to lack of training or dissatisfaction at workplace.

As a whole, employee turnover intention can be directly associated with low job satisfaction because dissatisfied workforce is always in search of an alternate employment. In order to stop the employees from looking at greener pastures and reduce their turnover intention, it is imperative for the employers to be people oriented also, rather is merely focusing on end results. It is a proven fact that happy workers do not intend shifting their job so easily. Similarly, employers also want their good employees to continue to work with them. Employee job satisfaction, turnover intentions and other factors have been discussed in the ensuing paragraphs.

\subsection{Role of Job Satisfaction on Turnover Intention}

Being the most important resource, employees have always been the focus of employers. The significance of HR has been amply highlighted by many scholars and there is a wealth of literature on employee motivation, job satisfaction and employee turnover intention, across the globe. Even in a developing country like Pakistan, there is no exception and a lot of research has been conducted by the academia and the practitioners alike. Due to obvious importance of human resource for an organization and turnover intention, there is an ongoing struggle by the employers to keep their employees happy, loyal and committed, both in developed and developing world. Job satisfaction leads to reduced turnover intention whereas turnover intention of an employee is encouraged by the factors causing de-motivation including those present at workplace (e.g. job itself, non-supportive peers, least bothered supervisors and the firm having non-conducive culture), or those factors which are related to individual employee (e.g. degraded performance or high rate of absenteeism (Bigliardi, Petroni \& Ivo Dormino, 2005). If an employee leaves an organization, it adds negatively in the index of organizational effectiveness (Staw,1980). As per the study of Cordery J. (2006), on Strategies for Improving Employee Retention, there are increasing challenges for the organizations in retaining skilled and effective employees and therefore companies need to devise a robust strategy for employee retention. According to a study, by Tan et al. (2007), on Singaporean companies, it was found that there were three categories of factors responsible for employee turnover intention; these factors included 'demographic factors' - e.g. age, gender, marital status and number of children, 'organizational factors' - e.g. length of service, salary and number of staff and 'attitudinal factors' - e.g. job satisfaction, work stress and level of commitment in the organization.

According to Zeynep \& Huckman, (2008), the issue of employee turnover has received significant attention, both by the managers and the academics. They have focused more on the reasons behind turnover intention of employees than just the turnover rate. They have assumed that there are some recognizable characteristics of workers, tasks, firms, and the markets, which are responsible for the employee turnover intention. The turnover rate can be brought down to the minimum if management 
succeeds in addressing these varying characteristics. As cited by Shoaib M., Noor A., Tirmizi S.R \& Bashir S. (2009), there is a positive relationship between factors like career development opportunities, supervision support, working environment, rewards, work-life policies and the employee retention, because these practices help employees in fulfilling their professional and personal needs.

As mentioned in a number of studies, managing turnover intention is not an easy task but a challenging one because different measures are taken for varying scenarios and no single approach may be equally useful for al organizations (American Management Association, 1999). Most of the factors, responsible for employee turnover intention, that have been commonly narrated in the literature include career growth opportunities, workplace environment, rewards system, managerial support and work-life balance.

\subsection{Career Growth Opportunities}

It is basic right of an employee to choose a career of own choice. Employers are expected to provide opportunity to the employees to grow in their career. Although, it is important consideration for a growth oriented employee; career development is an effort initiated by the organization aimed at striking a balance between career needs of employees and the growth requirements of the organization (Leiboiwitz et al, 1986). It is a new challenge for HR professionals to identify the career development needs of employees and then to devise appropriate strategies to help them achieve career milestones; this helps in achieving employee commitment towards organization's mission and strategic goals by maintaining a competitive edge over competitors (Graddick, 1988). Career development is considered to be a process that is beneficial for both the employee and the organization as it leads to important outcomes for the two parties (Hall, 1996; Kyriakidou and Ozbilgin, 2004). According to Butler and Waldrop (2001), career growth and employee development are about creating opportunities for the employees within the organization where they can nurture their career goals. It also involves provision of skill development and training opportunities aimed at helping employees in enhancing their employability within and outside the firm. While it is an essential requirement of a company to have a pool of talented employees to maintain a competitive advantage, employees also need to have appropriate career opportunities available for further developing their competencies. Employees expect their managers to create better job opportunities for them in return for the work they perform and the help they extend to enable the organization in achieving its goals (Prince, 2005).

\subsection{Workplace Environment}

Workplace environment refers to a set of behaviors, ethics, values, sense of comradeship, mutual support etc. which play a significant role in keeping the employees happy and committed. Workplace environment gets affected negatively, if factors like job itself, co-workers, work setting, attitude of the supervisor and the like are perceived to be inappropriate. Similarly factors related to individual employee, such as poor performance or high absenteeism rate can have adverse effect on the turnover intention 
(Bigliardi, Petroni \& Ivo Dormino, 2005). An empirical research conducted under the aegis of American Society for Interior Designers (ASID) supported that work environment can have a significant influence on employee turnover intention; numerous similar studies have confirmed the role of working environment in employee turnover intention (Laffaldano \& Mushinsky, 1985). Characteristics of work environment are not constant and usually vary from industry to industry; managers should develop a culture that can best suit their specific nature of work environment. Dissatisfaction of individuals with some aspect of work environment (e.g. including job, co-workers or organization) is likely to encourage them for turnover intention. Similarly, if organization is not satisfied with some aspect of the employee job, such as poor performance, absenteeism, attitude towards job etc., the employee would lose the job (Bigliardi, Petroni \& Ivo Dormino, 2005). According to a study, undertaken by Carmeli (2005), on social workers in health institutions, it was found that organizational culture providing challenging job, reduced employee's absenteeism, and supportive peers had an a strong influence on withdrawal intention of employees. Tan et al, (2007) conducted a comprehensive study on Singaporean firms and identified a number of variables connected with employee turnover intention; these factor have been split in three categories - employee demographic (e.g. age, education, gender, marital status and number of children), organizational factors (service tenure, monthly salary and number of staff members) and attitudinal factors (job satisfaction, work-related stress and organizational commitment).

Provision of suitable workplace environment commensurate with the nature of work is an essential obligation of an organization. Turnover intention has usually been debated as a phenomenon of critical nature because of its negative influences on organizational performance (Morrow \& McElroy, 2007). In case of education sector, teachers' turnover negatively influences overall quality of an education system and students' scores in exams (Ingersoll, 2001). Conducive, supportive and enabling culture is considered to be as factors that can help in reducing teachers' turnover intention (Certo \& Fox, 2002; Chittom, \& Sistrunk, 1990; Futrell, 1999; Kirby \& Grissmer, 1993). Besides, other factors including empowerment and job autonomy are also likely to create better employee satisfaction, leading to emotional encouragement, which would ultimately result in more engagement of employees (Watkins \& Marsick, 1993).

\subsection{Rewards and Recognition System}

Rewards and recognition system of an organization plays a significant role in enhancing employee motivation, commitment and reducing turnover intention. The term 'reward' has been discussed quite often the past and current literature as something that the employees receive as a compensation of their performance on the organization and also something which is desired by the employees (Agarwal, 1998). Organizations which recognize the contribution of employees and are perceived to have a fair equity based rewards distribution system can reduce turnover intention to a great extent (Arthur, 1994), Huselid, (1995).

According Kreitner (2004), financial rewards are said to be better motivators for those employees who seek protection through material resources. On the other hand, 
intend to seek satisfaction from challenging job. A number of studies have confirmed that competitive wage and rewards system enhances the motivation leading to high probability of employees to continue their employment in the organization (Shaw et al., 1998; Guthrie, 2001). According to a survey, conducted by Watson Wyatt (2002), on employee attitudes towards employers and workplace, a total of 12750 respondents belonging to different cadres of the large firms agreed that rewards and recognition helped them reduce turnover intention.

According to another study, by Ramlall S. (2003), aimed at identifying the determinants responsible for employee turnover intention, a number of reasons were observed for employee decision to leave an organization or continue to work. The study focused on importance of different retention practices to hold back critical employees. The research also focused on the cost per employee turnover and found out that the total cost amounted to approximately $150 \%$ of an employee's salary. Among other factors responsible for employee turnover intention, compensation package was found to be an important consideration for an employee's decision to either leave or stay back in the organization.

Hope J.B and Mackin P.C (2007) conducted a comprehensive research on "Determining differences between employee turnover rate of large and small firms" and it was revealed that large firms having better wages \& rewards had low turnover rate as compared to their influence on employees' turnover rate in small firms. As such, large organizations can ensure long term retention of their employees more effectively than the small organizations.

\subsection{Managerial Support}

By nature, employees prefer a work setting that involves interaction with colleagues, subordinates and superiors. Being an important factor for employee motivation, social support by peers in general and managerial support in particular creates a sense of comradeship within a team, department or an organization. Managerial and supervisory support is a major contributory factor for enhancing motivation and reducing employee turnover intention. New entrants always look towards their managers and supervisors for support in skill development, career counseling and career development. Through sincere efforts, managers can create a strong relationship with subordinates which ultimately act as a bondage that reduces turnover intention (Eisenberger, 1990). By working closely with subordinates, managers afford them opportunity to develop existing and learn new skills. This helps in smooth career progression of employees, leading to enhanced job satisfaction and reduced turnover intention (Russell and McManus, 1997). A research conducted by Seta et al. (2000) has concluded that among other factors like nature of work, rewards, and relationship with co-workers, managerial support and work supervision also contribute, to a large extent, towards enhancing job satisfaction. In a work environment where managers are supportive, encourage their subordinates for learning new skills and help them in meeting career milestones, job satisfaction increases and turnover intention reduces (Smith, Eisenberger and Shanock, 2006). 
According to a study conducted by Bishop \& Scott (1997) and quoted by Aamodt (2004), employee satisfaction was related to managerial support and which further resulted in organizational and team commitment, leading to higher productivity and lower turnover intention. Many researchers have disclosed that employees need supervisors who understand their needs, provide them required support and treat them on the basis of equity and justice. On the contrary, managers who display rude and indifferent attitude towards their subordinates have to face de-motivated employees who do not contribute to the best of their abilities. Employees who receive expected managerial support, whether, formally or informally, and who feel valued and respected, shall display productive behavior in the form of low absenteeism, job involvement, and reduced turnover rate. Such employees take part in all activities of the organization, helping it to achieve company targets. Employees having good academic record and possessing excellent skills may find a lot of employment opportunities outside the organization but specific work environment and strong bondage between manager and employees shall stop them from leaving by reducing their turnover intention (Freyermuth, 2007). Managers having high sense of organizational ownership shall always go ahead beyond their normal call of duty and job description and help their subordinates even in private matters in order to create more cohesiveness at workplace. As mentioned by Kim (2002), participative management that involves effective supervisory communication can increase employees' job satisfaction, leading to reduction in turnover intention. According to a meta-analysis conducted by Wagner and LePine (1999), the influence of job participation and managerial support is quite significant on employee job satisfaction. Similarly, Daniels and Bailey (1999) also found out that when supervisor involves employees in participative decision making, satisfaction level enhances and turnover intention reduces.

\subsection{Work-life Balance}

In the recent past there has been a greater emphasis on protecting human rights in every aspect of life. The issue of leading a balanced life has also gained much support in the developed business world. Although the idea was initially floated in the developed world, being an area of common concern for the people living anywhere in the world, it has quickly spread all over the globe. Both the employers and employees have realized that their long term association and healthy workplace environment is only possible if employees are facilitated in maintaining a balance between work life and family live. According to a study by Deery M. (2008), work-life balance plays an important role in employee intention to leave an organization or stay back. The study focused at importance of employee attitudes including organizational commitment, job satisfaction and work-life balance. The study concluded that healthy work-life balance measures proved more effective in employee turnover intention than the other factors. As cited by Cappelli (2000), the factors like career development, work environment and worklife balance are believed to have a direct impact on employee turnover intention. A study, undertaken by Aslam R. et al. (2011), has drawn a relationship between worklife conflict and turnover intention, in Pakistani culture. It was found that there was a weak relationship between work-family conflict and employee retention and that 
employee do not leave the job even if family-work conflicts exist.

According to Mulvaney (2006) and Clieveland et al. (2007), personal traits of employees, organizational culture, and supervisory support are related to the conflict both at workplace and family life. If remain unresolved, these conflicts further lead to employee intention to either leave the organization or stay back. Robert (2005) has mentioned that growth and prosperity of an organization depend upon employee commitment, loyalty, job satisfaction and active involvement in all matters of interest to both the organization and the employees. He further goes on to say that employee burnout and stress at workplace are detrimental to organizational success. To curb this tendency, many firms have started introducing work-life balance programs aimed at helping employees in striking a balance between work life and private life. According to Lockwood (2003), the organizations which take initiative to chalk out work-life balance programs for the employees are said to have created a win-win situation; the peace and comfort, which an employee enjoys by leading the balanced life, which ultimately leads to more commitment, enhanced performance and reduced turnover intention.

\subsection{Hypotheses}

On the basis of independent variables, duly supported by the literature, five hypotheses were developed:

Ho1: There is no relationship between career growth opportunities and turnover intention.

Ha1: There is a significant inverse relationship between career growth opportunities and turnover intention. intention.

Ho2: There is no relationship between workplace environment and turnover

$\mathrm{Ha}_{\mathrm{a}}$ : $\quad$ There is a significant inverse relationship between workplace environment and turnover intention.

Ho3: There is no relationship between rewards \& recognition system and turnover intention.

Ha3: There is a significant inverse relationship between rewards \& recognition system and turnover intention.

Ho4: There is no relationship between managerial support and turnover intention.

$\mathrm{Ha}_{4}$ : There is a significant inverse relationship between managerial support and turnover intention. 
Ho5: There is no relationship between work-life balance and turnover intention.

Ha5: There is a significant inverse relationship between work-life balance and turnover intention.

\subsection{Theoretical Framework}

(See figure in apendix)

\section{RESEARCH METHODOLOGY}

\subsection{Research Type and Data Collection Technique}

The research, being explanatory in nature, is based on primary quantitative data collected from respondents of six Bahria Schools/Colleges with the help of a well structured questionnaire.

\subsection{Target Population}

Presently a total of 932 teachers (population) are serving in Bahria Colleges. Out of these, 492 are the female teachers whereas remaining 440 are male teachers.

\subsection{Sample Size and Sampling Technique}

Data was collected from 120 teachers out of which 70 (58\%) were females and remaining $50(42 \%)$ were male teachers. It was found that number of female employees in Bahria Schools and Colleges was more than the male teachers. The sampling technique used was non-probability convenience sampling technique (See Table-1 in APPENDIX).

\subsection{Treatment of Quantitative Data}

The quantitative data collected through questionnaire were treated by applying statistical tools, Correlation and Regression, with the help of SPSS version 22.

\section{DATA ANALYSIS}

All hypotheses were tested by using 'Correlation' and 'Regression Analysis' tools; results and interpretation are given in the ensuing paragraphs.

\subsection{Correlation}

Statistical tool correlation is considered appropriate for determining the relationship of the independent variables with and dependent one. This statistical instrument commonly used to find out the degree to which each independent is linearly associated with dependent variable (William, and Anuchit, 2002). Having collected primary data 
with he help of survey questionnaire, correlation tool was applied to determine the extent to which different factors like Career Growth Opportunities, Workplace Environment, Rewards \& Recognition System, Managerial Support and Work-life Balance had relationship with Turnover Intention (See Table-2 in appendix).

$\mathrm{PC}=$ Pearson Correlation; $\mathrm{N}=$ Number of respondents; $\mathrm{S} 2-\mathrm{t}=$ Sig. (2-tailed); $\mathrm{CGO}=$ Career Growth Opportunities; WE $=$ Workplace Environment; RRS $=$ Rewards \& Recognition System; MS = Managerial Support, WB= Work-Life Balance, TI= Turnover Intention

\subsubsection{Interpretation}

Table 2 indicates the correlation between five factors and turnover intention. A significant inverse relationship has been found between first four factors and turnover intention. The first factor 'Career Growth Opportunities' has value of $\mathrm{r}=-.726$ at $\mathrm{P}<$ 0.01; it indicates that one unit increase in CGO corresponds with .635 points decrease in TI. The second factor 'Workplace Environment' has value of $\mathrm{r}=-.813$ and $\mathrm{P}<0.01$; it indicates that one unit increase in WE corresponds with .813 points decrease in TI. The third factor 'Rewards \& Recognition System' has the highest value among others i.e. value of $\mathrm{r}=-.867$ at $\mathrm{P}<0.01$; it indicates that one unit increase in Rewards \& Recognition System corresponds with .867 points decrease in TI. The fourth factor i.e. 'Managerial Support' has value of $r=-.653$ at $\mathrm{P}<0.01$; it indicates that one unit increase in MS corresponds with .653 points decrease in TI. In case of fifth factor i.e. 'Worklife Balance', the value of $\mathrm{r}=-.371$ but value of $\mathrm{P}=.061$ ( $\mathrm{p}>.01)$; it indicates that one unit increase in WB corresponds with .371 points decrease in TI whereas value of $p$ being greater than 0.01 shows that inverse relationship of WB with TI is not significant. Hence, with the help of Pearson Correlation results, it is proved that the first four factors have significant inverse relationship with teachers' turnover intention whereas the last factor, i.e. work-life balance, has a weak inverse relationship with employee turnover intention which is not significant. Thus first four hypotheses have been accepted whereas the last one stands rejected.

\subsection{Multiple Regression Analysis}

\section{(See Table-3 in APPENDIX)}

Statistics in table 3 indicate the value of correlation coefficient $\mathrm{R}$ and the coefficient of determination $\mathrm{R}$ square. This regression model is significant at 0.01 . The coefficient of determination has value of 0.68 , which indicates that impact of independent variables on teachers' turnover intention is only $68 \%$. It means that there are some other factors, not part of study, which also have $32 \%$ influence on teachers' turnover intention (See Table-4 in APPENDIX).
a.
Predictors: CGO, WE, RRS, MS, WB
b.
Dependent Variable: Turnover Intention (TI)

In order to further test the hypotheses, a multiple regression tool was applied to 
ascertain the variance in dependent variable as a result of change in different independent variables. Resultant values are presented in Table 4 and explained below:

\subsubsection{Interpretation}

The multiple regression analysis result (table 4) indicates different values, against each of the five independent variables, which help in accepting or rejecting the hypotheses. Details are discussed under each hypothesis:

\section{Hypothesis-1:}

$\S$ Career Growth Opportunities (CGO): In case of Career Growth Opportunities, the beta value is -.085 and $\mathrm{p}$ value is .001 which is less than 0.05 ; it indicates that there is a significant negative (inverse) relationship between Career Growth Opportunities and Turnover Intention. Hence, first hypothesis is accepted.

\section{Hypothesis-2:}

$\S$ Workplace Environment (WE): Here in this case, beta value is -.074 and $\mathrm{p}$ value is .000 which less than 0.05 i.e. $\mathrm{p}<0.05$; it shows a significant negative between Workplace Environment and Turnover Intention. Hence, second hypothesis is accepted.

\section{Hypothesis-3:}

$\S$ Rewards \& Recognition System (RRS): In this case, beta value is -.087 and $\mathrm{p}$ value is .000 which less than 0.05 i.e. $\mathrm{p}<0.05$; it indicates a significant negative relationship between Rewards \& Recognition System and Turnover Intention. Thus, third hypothesis is accepted.

\section{Hypothesis-4:}

$\S$ Managerial Support (MS): Here in this case, beta value is -.049 and $p$ value is .001 which is less than 0.05 i.e. $\mathrm{p}<0.05$; it indicates a significant negative relationship between Managerial Support and Turnover Intention. Hence, our hypothesis is accepted.

\section{Hypothesis-5:}

$\S$ Work-life Balance (WB): The beta value, is -.031 and $\mathrm{p}$ value is .061 which is > 0.05; it indicates that the negative relationship between Work-life Balance and Turnover Intention is not significant; the last hypothesis is rejected.

\section{FINDINGS}

Results obtained through statistical tools, 'Pearson Correlation' and 'Multiple Regression' indicate that all independent variables (i.e. CGO, WE, RRS, MS, WB) are having an inverse relationship with employee turnover intention. However in case of last variable (WB), although the relationship is negative but value of $\mathrm{p}$ is greater than 
0.05 . Hence, any change in WB has no significant influence on teachers' Turnover Intention. Detailed findings, in respect of each of the five hypotheses, are further discussed in the ensuing paragraphs.

\section{$\S$ Hypothesis-1}

First independent variable i.e. 'Career Growth Opportunities' is having significant impact on the employees' turnover intention. It means that if the schools and colleges can manage to create enough opportunities for career growth and development of teachers, they can ensure significant reduction in overall turnover intention of teachers. Conversely, institutions where teachers do not find sufficient opportunities for their career growth shall resort to leaving the present employer as soon as they find a better alternative; this will result in high turnover intention.

\section{$\S$ Hypothesis-2}

Second factor considered for the study i.e. 'Workplace Environment' is perceived to be of immense importance for the teachers' satisfaction if suitably handled; leading to their reduced turnover intention. Education institutions therefore need to create and maintain a conducive and supportive workplace environment where teachers can work with pleasure, pride and honor. High level of comradeship, cohesiveness and trust within peers and between management and teachers can significantly reduce turnover intention. Such an environment can easily be created with mutual support of teachers, headmasters, VPs and the top management.

\section{$\S$ Hypothesis-3}

Third variable 'Rewards \& Recognition System' is again of immense importance and, indeed, of top priority. Given the high inflation and ever soaring prices of commodities, financial rewards have become more lucrative for the teachers. Merit based rewards are the basis for an employee to develop a perception of an ethical organization that rewards its employees with fairness and equity. Teachers of bahria schools and colleges can be further motivated to continue to serve if they are suitably appreciated and rewarded for better performance. As we know, recognition and rewards system of an organization plays a significant role in ensuring long term employment status of good teachers. Rewards \& recognition system includes not only monitory benefits but also non financial incentives in the form of appreciation, empowerment, supervisory role and opportunity to perform multiple roles.

\section{$\S$ Hypothesis-4}

As far as fourth factor i.e. 'Managerial Support' is concerned, teachers of bahria schools and colleges view it quite useful for their smooth professional growth and career progression. By providing necessary support, Principals and Vice Principals can further maintain long term relationship with teachers, which is likely to result in better performance, commitment and loyalty. While such managerial support is compatible 
with psychological contract between employee and employer, the same is also likely to result in low absenteeism and reduced turnover intention. The significant relationship between managerial support and employee turnover intention indicates that perhaps teachers of Bahria schools and colleges do get sufficient attention of their headmasters, VPs and Principals.

\section{$\S$ Hypothesis-5}

The last independent variable 'Work-Life Balance' is although gaining lot of popularity in almost all leading organizations of the developed world; it does not seem to be on the priority list of either teachers or the management at Bahria Schools and Colleges. Given the prevalence of high inflation rate, unemployment and insecurity, most of the teachers, perhaps, do not attach much importance to WB. This may be related to specific Pakistani culture where employers are negligent of this important factor of reduced turnover intention. The male teachers were found to have less priority to timely go home and look after their families than to stay back in the organization, earn extra money and enhance take-home salary.

\section{CONCLUSION AND RECOMMENDATIONS}

Having conducted detailed analysis of the data, it can be concluded that all five independent variables considered for this study have inverse relationship with teachers' turnover intention (dependent variable) at Bahria schools and colleges. However, lack of awareness about 'Work-Life Balance', especially among male teachers needs to be further investigated. This can further be attributed to cultural constraint and financial hardship that teachers may be facing in Karachi. From Management's perspective, it is important to ensure that teachers are facilitated in creating a balance between workplace and family life, as it will help them in establishing better relationship with their institution; it will ultimately result in satisfied faculty that would help in raising overall standard of education. Since, rewards and recognition factor has higher scores, Bahria schools and colleges may further focus on this area and improve rewards and recognition system with an aim to remain competitive in fast growing private education sector. It will also be a step towards better employee-employer relationship and reduced employee turnover intention.

\section{FUTURE RESEARCH SUGGESTIONS}

Future researchers may like to delve on exploring more factors that may have strong relationship with teachers' turnover intention at Bahria Schools and College. Moreover, a similar study may also be conducted on other private Schools and Colleges operating in Karachi. A comparative study between private and public Schools and Colleges shall afford an opportunity to identify best practices of each education sector. In order to determine the impact of different factors on turnover intention in a diverse culture, the study may be conducted in different provinces of Pakistan. 


\section{REFERENCES}

Abelson, M. A. (1987) Examination of avoidable and unavoidable turnover. Journal of Applied Psychology, 72, pp. 382-386.

Agarwal, N. C. (1998). Reward Systems: Emerging Trends and Issues. Canadian Psychology Journal, Vol 39 (1), pp. 60-70.

Arthur, (1994), Huselid, (1995). Effects of human resource management system on performance and turnover. Academic of Management Journal 37, pp. 670-687.

Aslam R. et al. (2011), Family Conflict: Relationship between work-life conflict and employee retention, Journal of Research in Business, Vol 1(2), pp. 18-29.

Bigliardi, B., Petroni, A. and Ivo Dormio, A. (2005). Organizational Socialization,career aspirations and turnover intentions among design engineers. Leadership \& Organization Development Journal, 26 (6), pp. 424-441.

Bishop and Scott (1997). Job insecurity, extrinsic and intrinsic job satisfaction and effective organization commitment, South African Journal of Business Management 36 (2), pp. 27-33.

Borman, G. D., \& Dowling, N. M. (2008). Teacher attrition and retention: A metaanalytic and narrative review of the research. Review of Educational Research, 78(3), pp. 367-409.

Cappelli, P. (2000), 'A Market-Driven Approach to Retaining Talent', Harvard Business Review, 78(1), pp. 103-112.

Certo, J., \& Fox, J. (2002). Retaining quality teachers. High School Journal, 86(1), p. 57.

Cordery J. (2006), Cordery, J. L. \& Burr, R. (2006). Motivation and Empowerment. In P. Murray, D. Poole, \& G. Jones (Eds). Contemporary Management Issues in Management and Organizational Behavior. Sydney: Thomson Learning.E

Crossman, A., \& Harris, P. (2006). Job satisfaction of secondary school teachers. Educational, Management Administration and Leadership, 34(1), pp. 29-46.

Deery M. (2008), Talent management; Work-life balance and retention strategies, International Journal of Contemporary Hospitality Management Vol. 20 (7), pp. $23-28$

DeLong, D. W. (2004). Lost knowledge: Confronting the threat of an aging workforce. New York, NY: Oxford University Press. 
Mulvaney (2006) and Clieveland et al. (2007), A Model of Work-family dynamics of hotel Managers. Annals of Tourism Research, 34 (1), pp. 66-87.

Dess, G. D. \& Show, J. D. (2001), Voluntary turnover, social capital and organizational performance. Academy of Management Review, 26 (3), pp. 446-56

Frese, M. (1985). Stress at work and psychosomatic complaints: a causal interpretation. Journal of Applied Psychology, 70, pp. 314-28.

Hope J. B. and Mackin P.C (2007), Êthe Relationship between Employee Turnover and Employee Compensation in Small Business. Washington, D.C.: SBA Office of Advocacy, 2007 (Internet resource).

Ingersoll, R. (2001). Teacher turnover and teacher shortages: an organizational analysis. American Educational Research Journal, Vol 38(3), pp. 499-534.

Kim (2002). Participative management and job satisfaction: Lessons for management leadership, Public Administration Review, Vol 62, pp. 231-241.

Klein and Kozlowski et, al., (2000). Multilevel Theory, Research, and Methods in Organizations, Jossey-Bass, San Francisco, CA.

Laffaldano \& Mushinsky, (1985). "Job satisfaction and job performance: A metaanalysis". Psychological Bulletin, 97(2), pp. 251-273.

Lockwood (2003). Work-life balance; Challenges and solution: Society for Human Resource Management Research Quarterly, Alexandria, VA.

Mobley, W.H./Griffeth, R.W./Hand, H.H./Meglino, B.M. (1979). Review and Conceptual Analysis of the Employee Turnover Process, Psychological Bulletin, 86, pp. 493-522

Morrow, P., \& McElroy, J. (2007). Efficiency as a mediator in turnover-organizational performance relations, Human Relations Journal, 60(6), 827-849.

Morrel, K. M., Loan-Clarke, J. \& Wilkinson, A. J. (2004). Organizational change and employee turnover intention; Vol 33(2), pp. 161-173

Osteraker (1999), Measuring motivation in a learning organization, Journal of Work Place Learning.

Prince, (2005). Career-focused employee transfer process; Career Development International, 10 (4), pp. 293-309.

Price, J.L (1977), The study of turnover, 1st edition, Iowa state University Press, IA, pp. 10-25. 
Ramlall, S. (2003). Organizational Application: Managing Employee Retention as a Strategy for Increasing Organizational Competitiveness, Applied H.R.M. Research Vol, 8(2), pp. 63-72.

Robbins, S. P. \& Judge, T. A. (2007). Organizational Behaviour (12 $2^{\text {th }}$ ed.) New Jersey: Pearson Education, Inc.

Seta, C. E., Paulus, P. B. \& Baron, R A. (2000). Effective Human Research relation: A guide to people at work ( $4^{\text {th }}$ ed.). United State of America: Allyn and Bacon

Shoaib M., Noor A., Tirmizi S.R \& Bashir S. (2009). Determinants of employee retention in telecom sector of Pakistan, Proceedings of 2nd CBRC, Lahore, Pakistan

Spector P. E., (1997). Job satisfaction: Application, assessment, causes, and consequences. London: Sage Publications.

Tan et al. (2007), Intellectual capital and financial return of companies, Journal of intellectual capital, Vol 8, No 1, pp. 76-95.

Watkins, K. E., \& Marsick, V. J. (1993). Sculpting the learning organization: Lessons in the art and science of systemic change. San Francisco, CA: Jossey-Bass.

Zeynep \& Huckman, (2008). "Managing the impact employee turnover on performance: The Role of Process Conformance". Organization Science, Vol.19, 1, pp. 5668 


\section{APPENDIX}

Table 1: Gender-based Distribution of Respondents

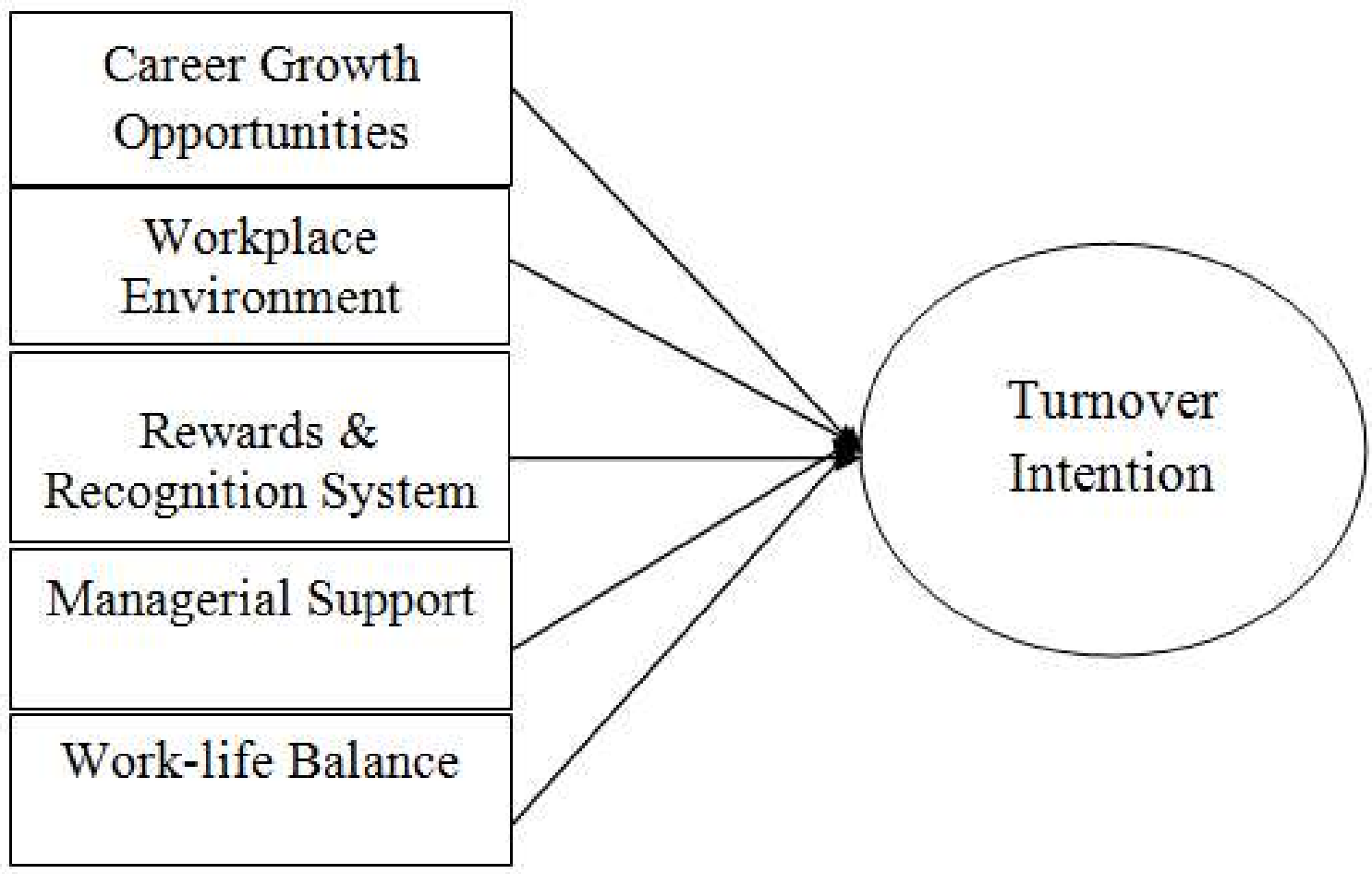

Table 2: Pearson Correlation

\begin{tabular}{|c|c|c|}
\hline Gender & Frequency & Percentage \\
\hline Male & 70 & $58 \%$ \\
\hline Female & 50 & $42 \%$ \\
\hline Total & $\mathbf{1 2 0}$ & $\mathbf{1 0 0} \%$ \\
\hline
\end{tabular}


Table 3: Summary of Linear Regression Model

\begin{tabular}{|c|c|c|c|c|c|c|}
\hline Variabl & CG0 & WE & RRS & MS & WB & TI \\
\hline \multirow{3}{*}{ CGO } & & $.613 * \%$ & $.732 \% *$ & $.509 * *$ & $.371 * *$ & $-.726^{k *}$ \\
\hline & & .000 & .000 & .000 & .001 & .000 \\
\hline & & 120 & 120 & 120 & 120 & 120 \\
\hline \multirow{3}{*}{ WE } & & & $.675^{* *}$ & $.635 * *$ & $.262 * *$ & $-.813^{* * *}$ \\
\hline & & & .000 & .002 & .000 & .001 \\
\hline & & & 120 & 120 & 120 & 120 \\
\hline \multirow{3}{*}{ RRS } & & & & $.747 * *$ & $.654 * *$ & $-.867^{* * *}$ \\
\hline & & & & .001 & .000 & .000 \\
\hline & & & & 120 & 120 & 120 \\
\hline \multirow{3}{*}{ MS } & & & & & $.552 \% *$ & $-.653^{* k}$ \\
\hline & & & & & .001 & .000 \\
\hline & & & & & 120 & 120 \\
\hline \multirow{3}{*}{ WB } & & & & & & $-.371^{* *}$ \\
\hline & & & & & & .061 \\
\hline & & & & & & 120 \\
\hline
\end{tabular}

** Correlation is significant at 0.01 levels (2-tailed)

Table 4: Multiple Regressions

\begin{tabular}{|c|c|c|c|c|c|c|}
\hline Model & $\mathrm{R}$ & $\begin{array}{c}\mathrm{R} \\
\text { Square }\end{array}$ & $\begin{array}{c}\text { Adjusted R } \\
\text { Square }\end{array}$ & $\begin{array}{c}\text { Std Error of } \\
\text { Estimates }\end{array}$ & $\mathrm{F}$ & Sig \\
\hline 1 & .827 & .683 & .690 & .364680 & 54.32 & .000 \\
\hline
\end{tabular}


Table 4: Multiple Regressions

\begin{tabular}{|l|c|c|c|}
\hline Independent Variables & Beta & T & Sig. \\
\hline $\begin{array}{l}\text { Career Growth Opportunities } \\
\text { (CGO) }\end{array}$ & -.085 & 1.064 & .001 \\
\hline Workplace Environment(WE) & -.074 & 1.083 & .000 \\
\hline $\begin{array}{l}\text { Rewards \& Recognition System } \\
\text { (RRS) }\end{array}$ & -.087 & 2.175 & .000 \\
\hline Managerial Support(MS) & -.049 & 1.023 & .001 \\
\hline Work-life Balance(WB) & -.031 & 1.210 & .061 \\
\hline
\end{tabular}

